\title{
Application of Zone Selective Interlocking in Electrical Power Distribution System
}

\author{
K. Shashidhar Reddy, M.Lakshmi Swarupa, D.Mamtha
}

\begin{abstract}
The two major concerns in today's electrical distribution system are the potential damage from fault stress and the costs associated with power outages. The optimal way to limit fault stress is to clear the fault in the shortest amount of time. Unfortunately, clearing the fault within the shortest amount of time might sacrifice coordination and lead to broader power outages. Zone Selective Interlocking Coordination assures the possible sustaining of faults for over currents and voltages with different faults. The circuit breaker operation and principle depend upon the open and close operation for the continuity of supply/service. To reduce the stress on the system, generated energy during fault conditions to be considered and its coordination to be checked.
\end{abstract}

Keywords: Distribution system, Zone selective interlocking, Coordination, MATLAB - SIMULINK.

\section{INTRODUCTION}

In the initial days of electricity, engineers developed circuit protective devices with a simple mission: To isolate overloads and faults. The prime goal was protecting the distribution system from damage- saving the wire. Engineers required to safeguard from fire and the collateral damage it might cause. The purpose of this strategy was simple: protection without consideration of uptime. So, the system provided protection, but it had a negative impact on reliability, which is not desired. Without selectivity, the circuit protective device nearest the fault may not be the one to clear the fault, resulting in larger power outages than needed.Later as technology and understanding developed, engineers tried to find out the ways to create circuit protection that also increased reliability, protecting against faults and overloads in a more precise or targeted manner.By eliminating the fault at the protective device nearest to the fault, engineers could provide protection with a minimal outage impact. Downstream circuit protective devices would be set to protect the load, while upstream breakers would have staggered time delays make the flow of the fault with

Revised Manuscript Received on December 30, 2019.

* Correspondence Author

Dr.K. Shashidhar Reddy, Electrical and Electronics Engineering Department, CVR College of Engineering, Hyderabad, India.

Dr.M. Lakshmi Swarupa, Electrical and Electronics Engineering Department, CVR College of Engineering, Hyderabad, India.

Ms.D.Mamtha, Electrical and Electronics Engineering Department, CVR College of Engineering, Hyderabad, India.

(c) The Authors. Published by Blue Eyes Intelligence Engineering and Sciences Publication (BEIESP). This is an open access article under the CC BY-NC-ND license (http://creativecommons.org/licenses/by-nc-nd/4.0/) selective coordination of the breakers.The engineering community's next step towards selectivity and uptime was zone protection-protecting a defined zone in the power distribution system. Instead of focusing on a single upstream/downstream path, zone protection identifies and eliminates faults only within a defined zone. Zone Selective Interlocking was first introduced to enhance selective coordination. In a ZSI Scenario [1], a downstream circuit protective device communicates with an upstream device when a current above the fault threshold is detected. Once the upstream device receives the signal, it "restrains" and shifts to a longer time delay, letting the device considers the upstream and downstream devices that provides back-up protection and operates instantly by presetting it's time delay. ZSI system communication is usually a nondigital Boolean signal over dedicated twisted pair wiring between the different devices for protection by considering the breaker trip individual units.

\section{SELECTIVE INTERLOCKING FOR ZONES}

The intercommunication system is designed to use different protective devices like relays, fuses and circuit breakers for power system in distribution zones by using Zone Restraint or Zone Selective Interlocking (ZSI). It can also be called as "All or Nothing Scheme". To improve the protection levels for high/low voltages and currents, the stress is to be limited for different faults like LG/LLG/LLL etc.

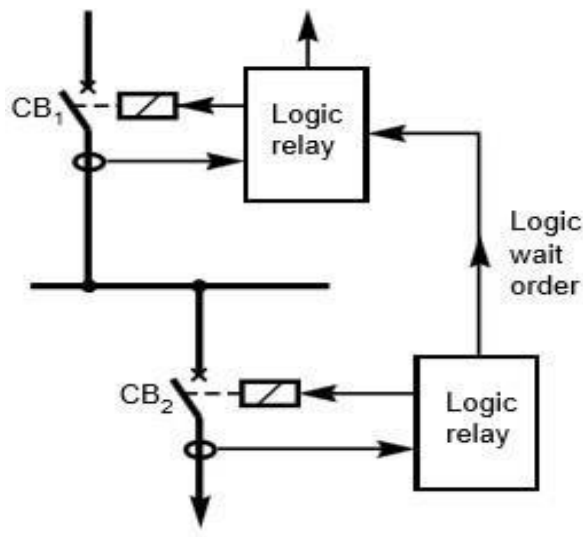

Fig.1. Zone Selective Interlocking

The test for the fault current over $2 \mathrm{X}$ is used to determine the next step. If there is no fault current, then all of the flags are cleared to make sure a clean start for the next time through the loop. If the fault current is detected, the ZSI output is enabled. The next test is to see if the Ground Fault or Short Delay protection is picked up. 


\section{Application of Zone Selective Interlocking in Electrical Power Distribution System}

If it is not, then the routine is exited. If either the G or SD protection is picked up, meaning that the value of fault current is over its setting, then the next test is to see if the protection has timed out. If the timing on the protection is done, then the breaker should be tripped and this is done.

If the timing is not expired, then there is a check of the ZSI on a coordinated system is the best solution to reduce costs associated with both fault stress and power outages.

\section{PRINCIPLE OF OPERATION}

To communicate with electronic trip devices, ZSI allows each other with isolated and clearing mechanism for upstream and downstream in circuit breaker with different faults and mainly ground fault. The analysis is considered with and without delay and with open/closed operation of power flow in the power flow diagram of distribution system. The main difference between without ZSI and with ZSI is that the fault clearing of circuit breaker is done with delay. The clearing time is considerably less with ZSI than compared without ZSI. The device nearer to the faults will be affected if short-time is considered at the time of protection and/or ground-fault delays can clear without considering delays which are intentionally obtained in power system. Limit current is also improved when ZSI with delay is considered for protection. The reduction in let-through energy can be as much as $86 \%$.

A system coordination study must be done to make sure that coordination exists. A system coordination study will establish settings and verify that pickup levels and delay times cascade downward, with the largest values at the main circuit level and smallest values at the branch circuit level. The electrical distribution system must be coordinated for any zone-selective interlocking scheme to work properly.

ZSI Logic:

The flow diagram in the figure below shows the logic flow of a typical protective unit with the ZSI function[2]. Not all units have the same logic. The protection routine is entered at the top. The first test is to see if a ZSI output signal should be sent ZSI input signal.

If there is a ZSI input signal exit and continue to do protection timing. If there is no ZSI signal, then check to see if this is the first time through the routine. If it is the first time, then the ZSI Zone Flag is set. If the logic gets to this point again the Zone Flag will have been set from the previous pass and there was no ZSI input signal, therefore the ZSI protective function will now do a quick trip of the circuit breaker. The 2 passes are important to make sure that transients or false signals are not interpreted as true signals to prevent any nuisance tripping or false blocking.

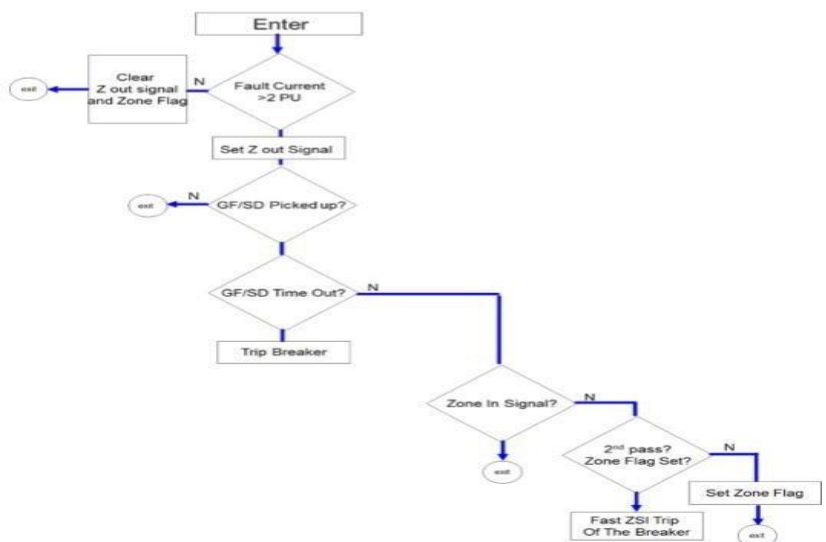

Fig. 2. ZSI Internal Logic Flow Chart.

\section{DIFFERENT KINDS OF FAULTS}

a) Feeder Fault:

The circuit breaker is a protection switch used for stopping malfunctioning and its blocking capacity of voltage and current for various time delays and interlockings are considered. The signal which will be blocked with the main circuit breaker to trip and reset as per the fault and time delay mentioned. The stress is the parameter which varies with the time and delay and the conditions and types of faults.

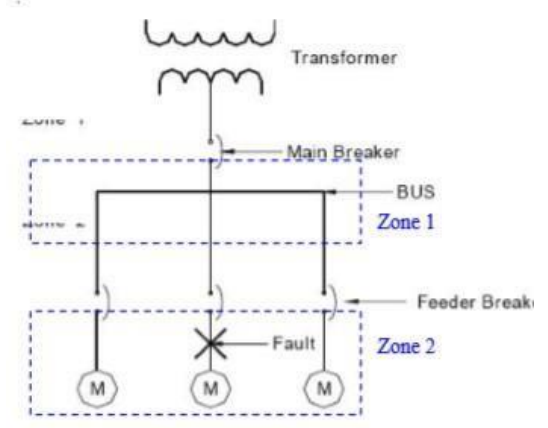

Fig 3: Feeder Fault.

b) Bus Fault

The advantaged of the Bus fault in the switchgear protection is changes the primary and secondary bus feeder distribution of the voltage and its working as per the fault and time delay. Depending upon the upstream and downstream of the fault occurring. in the system the blocking current of the signal changes.The electronic or mechanical tripping of the circuit breaker and its logic sequence changes as per the rides and the time delays and varies with the characteristics and tripping with and without delay. 


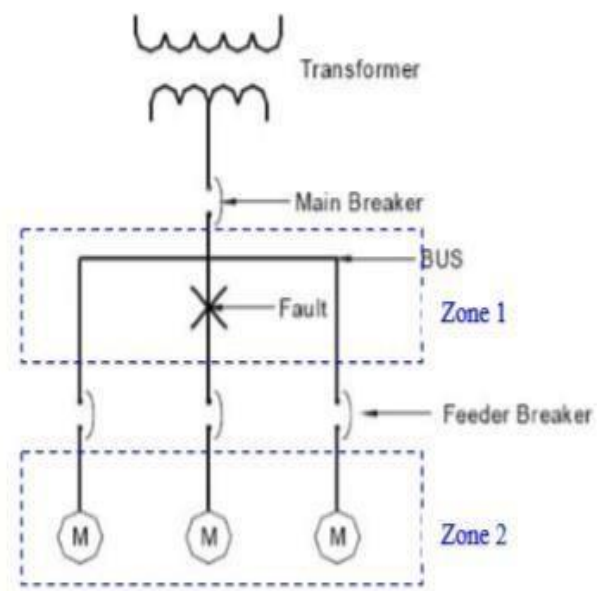

Fig. 4. Bus Fault.

\section{c) Self-Interlocking}

Over Load: If the Zone Selective Interlocking logic would be applied on an Over Load fault then it would lead ZSI to a nuisance technology. For instance, the breakers used in the downstream are of low rating and the breakers used in the upstream are of higher rating. When the load applied on the downstream breaker reaches the maximum limit or exceeds it then it would send the restraining signal to all the other breakers.

This is not intended as it would disturb the system coordination. Because of a breaker being overloaded the level of fault entering the system would be nothing more than $110-130 \%$ of the breakers full load capacity, before which the circuit breaker would trip. This is not a kind of fault which would damage the entire system.

Transformer Inrush Currents: Applying zone interlocking on the primary side of a transformer may cause false trips due to high transformer inrush currents that may be greater than $12 \mathrm{X}$ the FLA rating of the transformer with the secondary open. To prevent the breaker on the primary side from tripping in a nuisance condition a self-interlocking jumper should be installed during the energizing of the transformer, which can last from 10 cycles to several minutes.

This may be accomplished by using a timer that closes a contact during the inrush period of the transformer across the zone interlock output and input terminals of the device. If a harmonic restrain unit that monitors 2nd order harmonics is available; a contact closure from the harmonic restraining unit can be used as a self-interlocking jumper. The usage of self-interlocking jumper would allow the device to trip as per the preset coordinated time current curves and temporarily disable the instantaneous zone interlock feature.

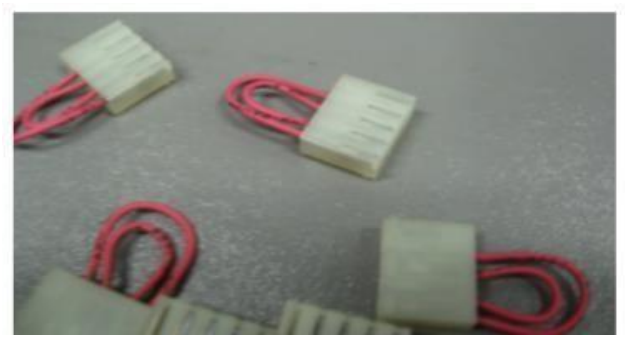

Fig. 5. Jumper Wires

\section{DEVICES CAPABLE OF ZSI}

Module of the Ground Fault: To protect against the electrical equipment and faults the ground fault protection is used and it is observed from case study that there are mainly two categories considered for the analysis i.e. phase-phase fault and ground-phase fault.

Electrical faults are of $98 \%$ of the total faults in nature and additional necessary protection against over and under current/voltage protection. In electrical circuits, current returns to its source. A current based ground-fault relay may look for ground-fault current in one of two ways mentioned below:

Zero sequence: Here, the relay looks at the phase conductors to ensure that all current coming from the source returns on those same conductors. If some of the current is returning to the source through a different path (usually ground), the ground-fault relay will detect this difference and, if it exceeds a pre- determined amount for a pre-determined amount of time, the ground-fault relay will operate.

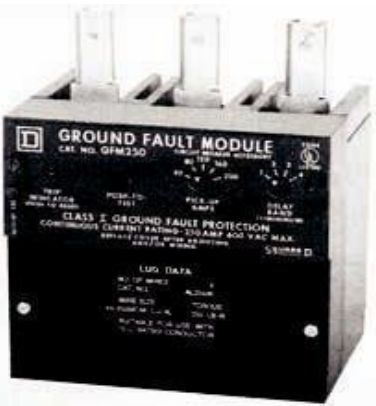

Fig. 6. Ground Fault Module.

Direct measurement: A ground-fault relay can also read the current in the connection between the transformer connections by considering ground and neutral. The commonly used type of grounding is resistor grounding. A ground fault anywhere in the system will return current through this path.

Ground Fault Modules are equipped with zone-selective interlocking as a standard feature. Since these devices are capable of sensing a ground fault only (and not a short circuit), they are capable of ground-fault zone-selective interlocking only. They are intended solely for branch circuit applications and have only ZSI outputs. They cannot receive restraint signals. Circuit Breakers with Microprocessor Trip Units: The mechanical switch used for protection for making and breaking of the switch for abnormal or over voltage and current conditions are obtained by circuit breaker.

There are two types of releases namely: Thermal Magnetic Release and Microprocessor based release.

As both perform in the same manner for Overload and Short Circuit, but in a microprocessor-based Circuit breaker we have an additional protection i.e. for Earth fault. Apart that the range of fault setting in a microprocessor-based circuit breaker is more than in a thermal magnetic trip unit [3]. So, in order to avoid the usage of "Ground Fault Module", "Microprocessor based release" type Circuit Breaker can be preferred. 


\section{Application of Zone Selective Interlocking in Electrical Power Distribution System}

If intended to use Thermal Magnetic Release type of ACB's or MCCB's then it becomes mandatory to make use of the Ground Fault Module.

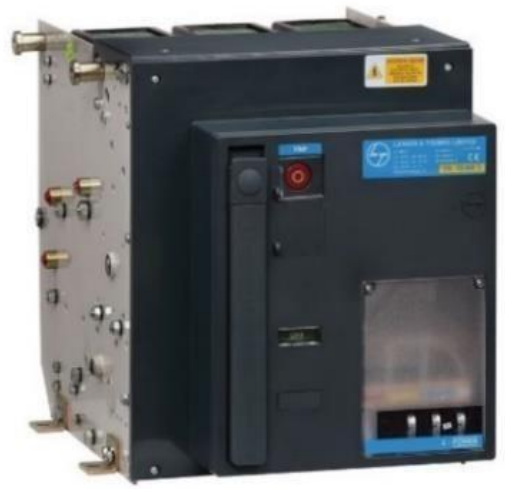

Fig. 7. Air Circuit Breaker

ZSI Relay: The terminals of the interconnection of the source protection from zonally is a classical approach for different fault conditions but the upstream and onstream analysis of the circuit breaker is consider by communicating with different interlink of the protection devices and the closet distance of the fault is also located.

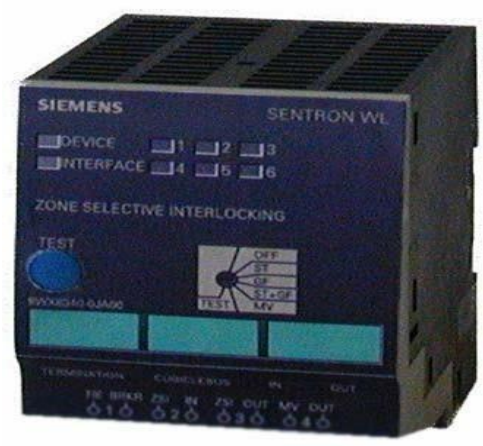

Fig. 8. Zone Selective Interlocking Relay.

Use of two sources Transformer and Generator both incorporated with Circuit Breakers. In order to maintain the coordination, we placed another circuit breaker in the form of Bus Coupler. In this circuit any two circuit breakers will be turned on while the other breaker will be turned off. As the supply further passes to the load, there are breakers further up for distribution.

Consider a case where all the faults to be executed with the very same setup.

a) A 250KVA Transformer incorporated with 320A FP MCCB 50KA as Incomer.

b) A 250KVA Diesel Generator incorporated with 320A FP MCCB 50KA as Incomer.

c) A 320A FP MCCB has been placed between these two to create coordination.

d) Four nos' of 100A FP MCCB 36KA have been placed in the system, which further feed to 32A TP MCCB 25KA, which are directly connected to the load. Here making use of the above-mentioned details we compare the discrimination of both Zone Selective Interlocking and Time-Based Discrimination under Short Circuit and Ground Fault Conditions.

During a fault at lower levels of the system:
- All circuit breakers (main, feeder, sub feeder, etc.) upstream of the fault will sense the fault. If the fault is above their pickup level, the feeder, sub feeder etc., will send a restraint signal upstream. The restraint signal activates the preset time delay on the upstream device.

- All circuit breakers downstream of the fault will not sense the fault and will not send a restraint signal upstream.

- Therefore, the preset time delay is activated on all circuit breakers upstream of the fault except the one closest to the fault.

- The protection device closes depending upon the fault condition and its timing signal by considering without and with delay.

- All other circuit breakers upstream of the fault, having received a restraint signal, will delay tripping for the time selected by their trip unit adjustment to maintain selectivity and coordination.

Thus, the only device that will trip in a ZSI system is the one closest to the fault, and it will do so with no intentional delay [4].

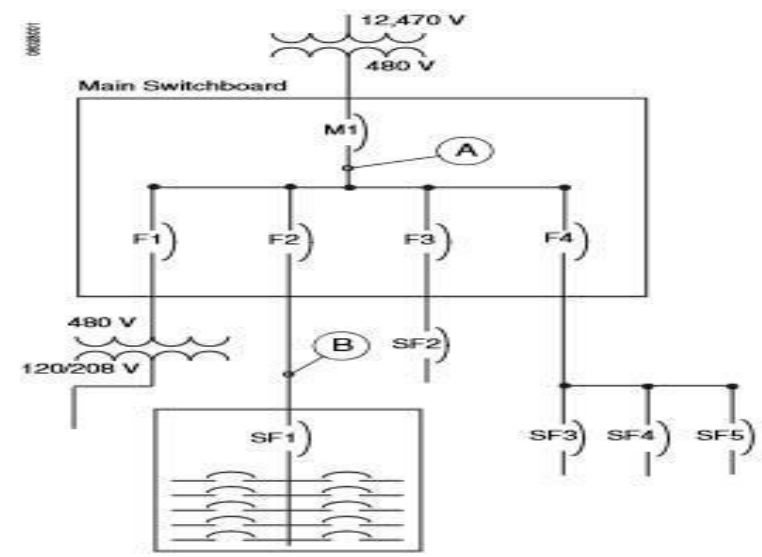

Fig. 9. Over Current Device Zone

ZSI OPERATION USING SIMULINK:

The following is the example of feeder fault:

- $\quad$ Both the 320A and 100A circuit breakers will analyze the fault caused. The circuit breaker of 32A (downstream of the fault) will not sense the fault.

- The circuit breaker with $100 \mathrm{~A}$ can be activated with preset and it transmits a restrained signal with time delay on the 320A circuit breaker and all the other 100A circuit breakers connected in series. The 320A circuit breaker begins to time out to the 0.5 second of least delay in time with consideration of its trip unit.

- The 100A circuit breaker does not receive a restraint signal, so its preset time delay is deactivated. The tripping is done without delay.

- The 100A circuit breaker will clear the over/under currents and voltages faults without delay. The upstream (320A) protective device will remain closed because the fault was cleared before its time delay expired. 
The outage was isolated to the upstream circuit breaker nearest the fault. Stress on the system was minimized because the fault was cleared with no intentional delay.

\section{ADVANTAGES:}

Zone Selective Interlocking preserves coordination between main, tie and feeder circuit breakers. It also allows for fast tripping within the protection zone without requirement worker intervention. As there is no intentional time delay, the tripping time is very fast because of which the life of switchgear and the life of the cables and other electrical equipment will not be damaged because of the fault in the system. Trouble shooting can be more efficient.

\section{DISADVANTAGES:}

ZSI doesn't let you obtain your desired arc flash energy level because of the need to coordinate settings by allowing time for the downstream feeder restraint signal to reach the upstream main. The speed of the operation is dependent on the relay plus the breaker speed. The added expense of equipment and implementation costs are the major drawbacks of the ZSI Technology.

\section{SIMULATION MODELS AND RESULTS}

\section{At Bus/Feeder:}

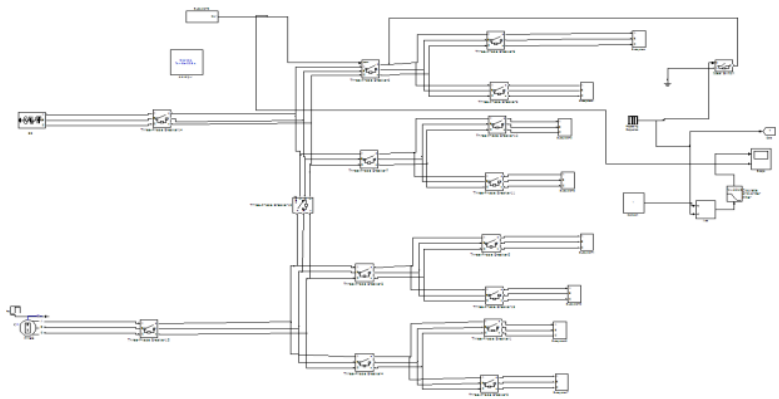

Fig 10: Simulation Model of Time based discrimination Ground Fault relays

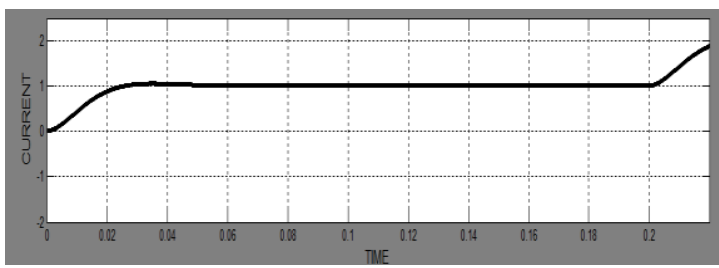

Fig 11: Time based Discrimination - Current Versus time for Ground fault relay - 1

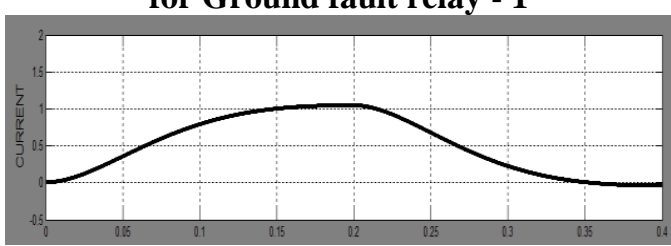

Fig 12: Time based Discrimination - Current Versus time for Ground fault relay -2

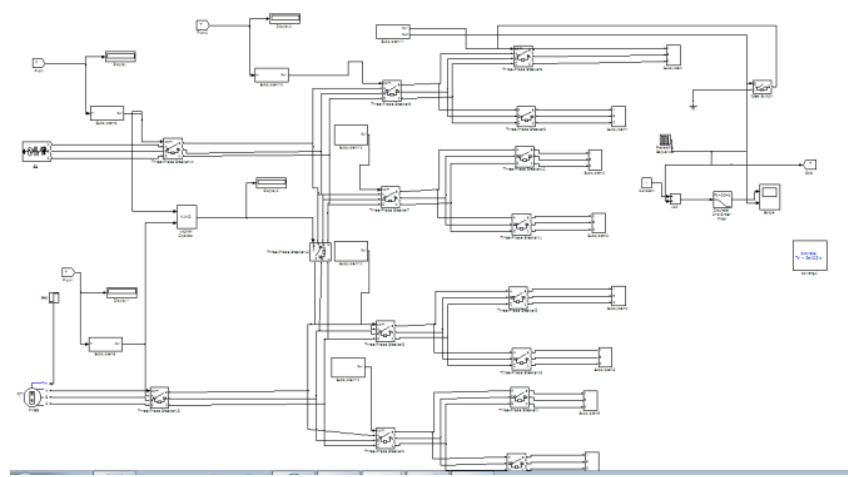

Fig 13: Simulation Model of Zone selective Interlocking Ground Fault relays

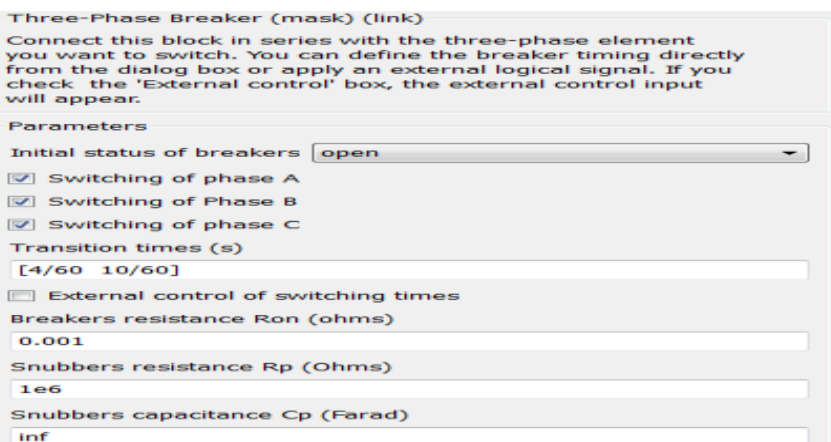

Fig 14: Relay is considering in the form of Circuit breaker with timing

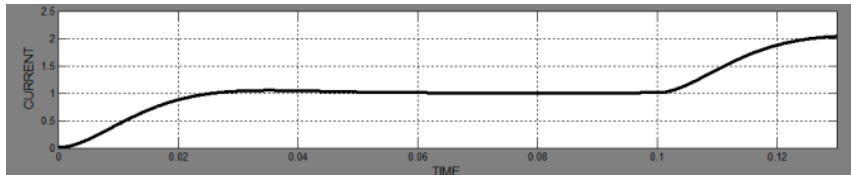

Fig 15: Zone selective Interlocking - Current Versus time for Ground fault relay - 1

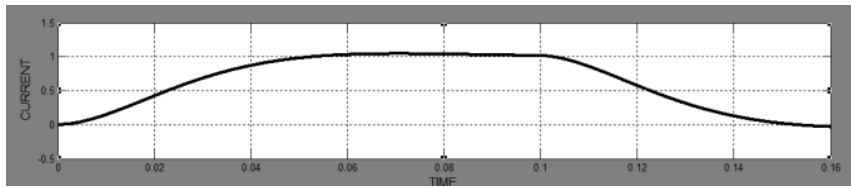

Fig 16: Zone selective Interlocking - Current Versus time for Ground fault relay - 2

\section{At Bus:}

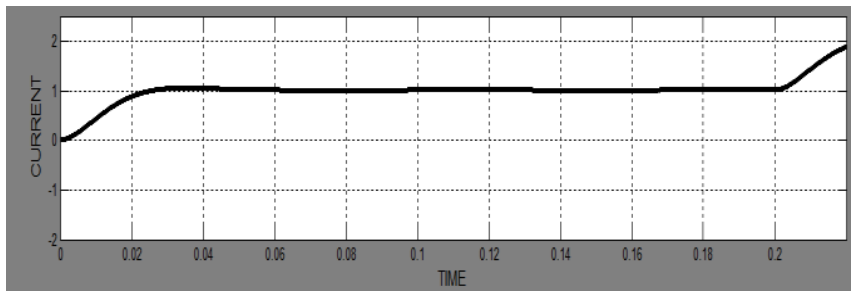

Fig 17: Zone selective Interlocking - Current Versus time for Ground fault relay - 1 
Application of Zone Selective Interlocking in Electrical Power Distribution System

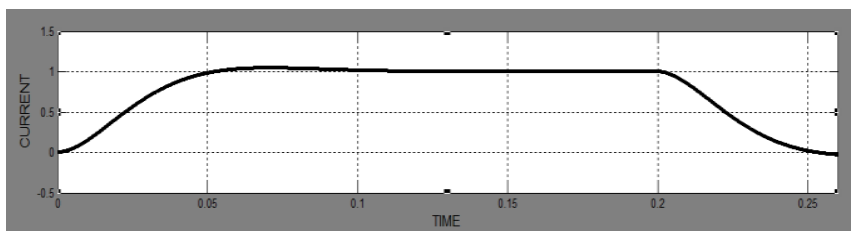

Fig 18: Zone selective Interlocking - Current Versus time for Ground fault relay - 1

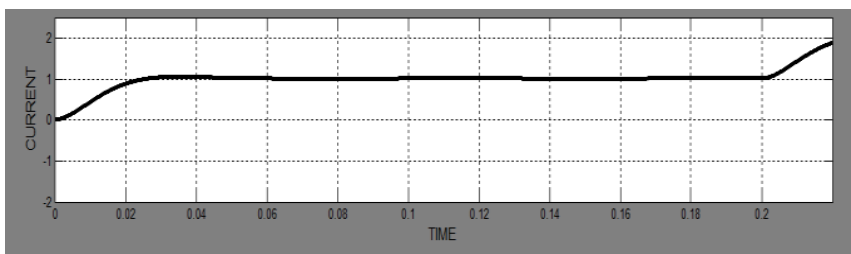

Fig 19: Zone selective Interlocking - Current Versus time for Short Circuit fault relay - 1

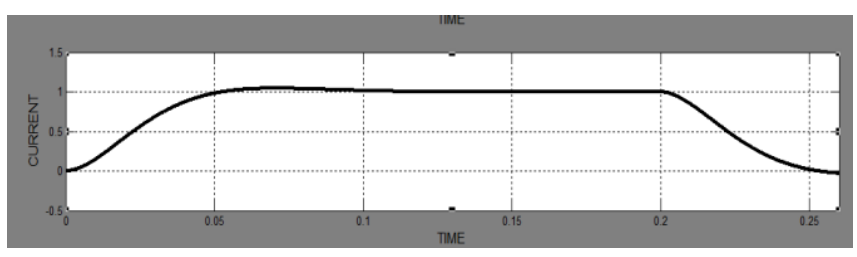

Fig 20: Zone selective Interlocking - Current Versus time for Short Circuit fault relay - 2

Table 1: Comparison Table for Tripping time with ZSI and without ZSI (At Bus/feeder)

\begin{tabular}{|c|c|c|c|c|}
\hline $\begin{array}{c}\text { Type of } \\
\text { Device }\end{array}$ & $\begin{array}{c}\text { Rated } \\
\text { current } \\
\text { (Amps) }\end{array}$ & $\begin{array}{c}\text { Short } \\
\text { delay trip } \\
\text { time } \\
\text { setting } \\
\text { (secs) }\end{array}$ & $\begin{array}{c}\text { With ZSI } \\
\text { Tripping } \\
\text { time in } \\
\text { secs) }\end{array}$ & $\begin{array}{c}\text { Without } \\
\text { ZSI } \\
\text { Tripping } \\
\text { time in } \\
\text { secs) }\end{array}$ \\
\hline $\begin{array}{c}\text { Feeder } \\
\text { Breaker }\end{array}$ & $100 \mathrm{~A}$ & $50 \mathrm{~ms}$ & - & - \\
\hline $\begin{array}{c}\text { Main } \\
\text { Breaker }\end{array}$ & $320 \mathrm{~A}$ & $80 \mathrm{~ms}$ & $\begin{array}{c}200 \\
\text { msecs. }\end{array}$ & $\begin{array}{c}260 \\
\text { msecs. }\end{array}$ \\
\hline
\end{tabular}

Without ZSI: From table 1 the upstream protection units are typically delayed to give the downstream protection units time to trip. When there are many levels of discrimination, the fault clearing time at the source is long. The fault clearing time for the protection unit furthest downstream is Xs, the fault clearing time at the source is $\mathrm{T}=\mathrm{Xs}+$ delay.

With ZSI: From above table 1 When a fault appears, the protection units that detect it block the upstream protection units. The protection unit furthest downstream trip since it is not blocked by another protection unit. The delays are to be set in accordance with the device to be protected. The fault clearing time for the protection device furthest downstream is $\mathrm{Xs}$, the fault clearing time at the source is $\mathrm{T}=\mathrm{Xs}$-time delay.
Table 2: Let-Through comparison between without and with ZSI

\begin{tabular}{|c|c|c|c|c|c|}
\hline $\begin{array}{c}\text { Faul } \\
\text { t }\end{array}$ & \multicolumn{2}{|c|}{ Without ZSI } & \multicolumn{3}{|c|}{ WITH ZSI } \\
\hline & $\begin{array}{c}\text { Trip } \\
\text { time } \\
(\mathrm{ms})\end{array}$ & $\begin{array}{c}\mathrm{I}^{2} \mathrm{t} \\
\text { Let-Throu } \\
\text { gh }\left(\mathrm{A}^{2} \mathrm{sec}\right)\end{array}$ & $\begin{array}{c}\text { trip time } \\
\text { unrestrain } \\
\text { ed (ms) }\end{array}$ & $\begin{array}{c}\mathrm{I}^{2} \mathrm{t} \\
\text { Let-Throu } \\
\text { gh } \\
\left(\mathrm{A}^{2} \mathrm{sec}\right)\end{array}$ & $\begin{array}{c}\text { Reduction } \\
\text { in } \mathrm{I}^{2} \mathrm{t} \\
\text { Let-throu } \\
\text { gh }\end{array}$ \\
\hline $\begin{array}{c}100 \\
\mathrm{~A}\end{array}$ & - & $0.1 \times 10^{6}$ & - & $0.1 \times 10^{6}$ & same \\
\hline $\begin{array}{c}350 \\
\mathrm{~A}\end{array}$ & 260 & $0.8 \times 10^{6}$ & 200 & $0.3 \times 10^{6}$ & $63 \%$ \\
\hline
\end{tabular}

Analysis: From above table 2 system coordination study must be done to make sure that coordination exists. A system coordination study will establish settings and verify that pickup levels and delay times cascade downward, with the largest values at the main circuit level and the smallest values at the branch circuit level. The electrical distribution system must be coordinated for any zone-selective interlocking scheme to work properly.

\section{CONCLUSION}

The need to act quickly to clear a fault and the need to provide coordinated protection require compromise in the selection and application of conventional overcurrent protection. A system with zone selective interlocking is coordinated the same as any other power distribution system. By selecting longer delay times for upstream circuit breakers, downstream circuit breakers can take chance to trip first. In addition, to the existing delays of ZSI the circuit breaker communication removes its functionality when fault is observed, which have delays for sudden interrupts. Tripping mechanisms are used commonly for reducing the current at different fault conditions and at different operations. The time taken for the fault current limitation is very low and varies at different fault conditions and the stress levels are also changed. The interlocking by zero-selection for the energy and power consumption w.r.t changes for the system for different fault conditions and results in prolonged equipment life. The focus of the new technologies is on fault conditions and its safety a precaution for the distribution system with different standards and objectives. ZSI is longstanding technologies that can be used to expedite otherwise slow time-overcurrent protection. The scheme can be implemented in many ways. Consider the failure mode of the scheme. Transformer inrush \& substations with multiple sources offer challenges to ZSI implementation. Choose your ZSI timing carefully.

\section{ACKNOWLEDGMENT}

We thank EEE faculty of CVR College of Engineering for helping in completion of this paper. We also thank management of CVR College of Engineering for permitting us for providing laboratory platform for doing simulations in CAD and Power Systems Lab.

\section{REFERENCES}

1. Zone Interlocking Application Note: Christopher G Walker, Eaton Corporation, Cutler-Hammer business unit.

2. Energy-based discrimination for LV protective devices Cahier Technique no. 167 R. MOREL - M.SERPINET.

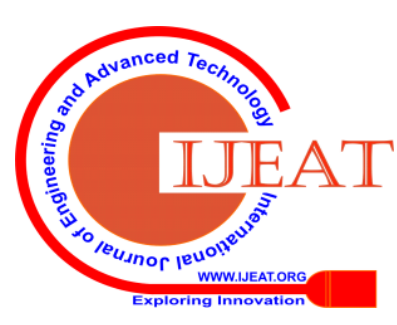


3. ARC-FLASH INCIDENT ENERGY REDUCTION USING ZONE SELECTIVE INTERLOCKING-Donna Lee Hodgson from Shell Exploration and Production Co.

4. H. J. Altuve Ferrer and E. O. Schweitzer, III (eds.), Modern Solutions for Protection, Control, and Monitoring of Electric Power Systems.

\section{AUTHORS PROFILE}

Dr.K. Shashidhar Reddy Graduated from JNTU in 2001. He had completed his M. Tech in Energy Systems from VTU, in 2003. He completed Ph.D. from JNTUH in 2015. He is working as a PROFESSOR in CVR College of Engineering, Hyderabad. He published more than 30 research papers in national, international journals and conferences. His areas of interest are Power Transformers, High Voltage Engineering, Renewable energy sources and Power Systems.

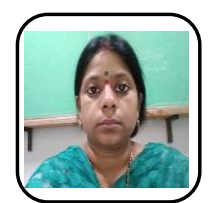

Dr. Malladi Lakshmi Swarupa received his B.Tech degree in Electrical and Electronics Engineering from B.V.R Institute of Technology, JNTU, Narsapur, India, in 2002 and her M.Tech in Control Sytems from JNTUCEA, Anantapur in 2005. She received her $\mathrm{PhD}$ degree in Electrical Engineering from JNTU, Hyderabad, India, in 2016. She has teaching experience of nearly 14.5 years. Currently, she is working as Professor in CVR College of Engineering, Telangana, India. She has published 42 research papers in various national and international journals and conferences. Her areas of interests are Microcontrollers, DSP, Control systems, neural networks, fuzzy logic, artificial intelligence, Reliability and so on.

Ms.D.Mamatha is a Post Graduate student of CVR College of Engineering, Hyderabad. Her areas of interest are Power systems, Renewable energy sources. 